\title{
The importance of standards in medicine
}

\author{
Paolo Raggi, MD, PhD ${ }^{\mathrm{a}}$ \\ a Division of Cardiology, University of Alberta, Edmonton, AB, Canada
}

Received Jul 9, 2020; accepted Jul 9, 2020

doi: $10.1007 / \mathrm{s} 12350-020-02288-w$

\section{See related article, pp. 126-135}

In the issue of the journal Tzolos et al. ${ }^{1}$ describe a new method to reproducibly measure the coronary artery activity of ${ }^{18} \mathrm{~F}$-sodium fluoride $(\mathrm{NaF})$. They performed two PET and CT angiography (CTA) scans 12-14 days apart in 19 patients with known coronary artery disease (CAD) and applied a semi-automated method that utilized a centerline approach along the course of the main epicardial coronary arteries to reconstruct a tubular volume around the coronary arteries. The NaF activity was measured within the tubular volume, hence this new method (coronary microcalcification activity: CMA) provided a global measure of the $\mathrm{NaF}$ activity along the coronary artery tree. They demonstrated a $100 \%$ agreement between scans and between reviewers for the presence or absence of $\mathrm{NaF}$ activity. Additionally, the interscan, intra-observer and interobserver coefficients of repeatability were all excellent. Of note CMA is based on maximum standardized-uptake-value (SUV) measurements rather than the more frequently reported target-to-background ratio (TBR). In the paper by Tzolos et al., ${ }^{1}$ CMA showed superior testing characteristics compared to TBR. What are the potential benefis and pitfalls of this new method? Molecular imaging with $\mathrm{NaF}$ has emerged as a new exciting approach to assess the presence of active processes of microcalcification in atherosclerotic plaques, ${ }^{2,3}$ In prior reports, NaF uptake was shown to be higher in patients at high risk of $\mathrm{CAD}^{4-6}$ it was associated with features of vulnerability on CTA, ${ }^{7,8}$ and in patients seen in the emergency department with an acute coronary syndrome or a recent cerebrovascular event $\mathrm{NaF}$ accumulated avidly in culprit

Reprint requests: Paolo Raggi, MD, PhD, Division of Cardiology, University of Alberta, 5A9-014, 11220 83rd Avenue NW, Edmonton, AB T6G 2B7, Canada; raggi@ualberta.ca

J Nucl Cardiol 2022;29:136-7.

$1071-3581 / \$ 34.00$

Copyright (C) 2020 American Society of Nuclear Cardiology. plaques. ${ }^{9}$ The same authors recently showed that $\mathrm{NaF}$ is a good predictor of future events in patients with known CAD. ${ }^{10}$ Although $\mathrm{NaF}$ has been in use for decades to identify bone metastases due to its affinity for growing crystals of hydroxyapatite, the discovery that it may identify patients at potentially high risk of cardiovascular events produced a wave of interest in this molecular imaging technique. Akin any new imaging approach, standardization is of paramount importance for the test to be applicable on a large scale and ultimately demonstrate its utility. The authors of the manuscript suggest that CMA should be considered similar to the Agatston score ${ }^{11}$ for assessment of burden of coronary atherosclerosis, and they may have chosen an appropriate comparator. In fact, the implementation of the Agatston score, and others that were developed subsequently with an improved reproducibility, made it possible to demonstrate the power of coronary artery calcium (CAC) as a predictor of events in a variety of scenarios and populations. There are currently several obstacles that prevent the wide implementation of nuclear molecular imaging, such as the need to have access to PET facilities (most tracers require a PET scanner for imaging), highly specialized radio-pharmacies, physicists, cyclotrons and, not inconsequentially, the lack of standards to assess the extent and severity of disease. Without standards it is practically impossible to set up collaborative research projects between centers and collect the quality and quantity of data necessary to make recommendations about the use and implementation of any imaging modality. Traditionally, and most frequently, the activity of $\mathrm{NaF}$ uptake (and other molecular tracers) is reported as TBR to obviate the variability in radiotracer dosing and activity at the site of interest. To calculate TBR the uptake in the "hot spot" of interest is compared to a "hot bed" with high tracer concentration such as the right atrium or the left ventricle (the blood pool). However, there is no agreement at this time as to what constitutes a high TBR. In the paper by Tzolos et al., ${ }^{1}$ for example, an area with a TBR $>1.25$ was considered sufficiently hot and therefore $\mathrm{NaF}$ positive. However, this assumption was 
arbitrary and not based on any outcome data of substance. By using a more robust tool based on quantification of SUV of all plaques along the coronary artery tree, the authors were able to achieve high reproducibility and therefore come as close as ever to a standardized approach. Nonetheless, there are still a few limitations in this method. In order to obtain a clear centerline in the coronary arteries every patient had to be submitted to CTA along with PET imaging. It is therefore important to obtain high quality CTA images to start. Although the radiation dose is rapidly decreasing with modern multidetector CT scanners, many centers would not have access to the most recent CT models, operators may not be trained in the most advanced techniques and CTA requires the use of intravenous contrast with its attendant risks. This study was conducted in patients with established multivessel CAD, and for any method to be implemented as a risk prediction tool in the general population, it would have to be tested in patients at risk of but without open CAD. CMA is not free of potential pitfalls and measurement errors such as those induced by motion artifacts while acquiring CTA images, calcification of the mitral valve ring that could be included in the circumflex coronary artery, activity in vessels with a diameter $<2 \mathrm{~mm}$ (vessels excluded in this analysis). Of course a screening tool should be made readily available at an acceptable cost to everyone to be widely implemented. Interestingly, the authors did not tell us how many patients with CMA $>0$ had no detectable CAC, or how many patients with $\mathrm{CMA}=0$ had a measurable amount of CAC. In a prospective follow-up study it would be important to know which marker is a more accurate predictor of events: evidence of active microcalcification accrual without macrocalcification (the first scenario), or macrocalcification in the absence of micromolecular activity (the second scenario)? Only prospective long-term studies may be able to answer these questions. Although there are several outstanding questions, the method presented in the article by Tzolos et al. ${ }^{1}$ opens the doors to a new opportunity for molecular imaging to be applied to outcome studies in search of patients harboring unstable coronary artery plaques. At the same time a highly reproducible method could be implemented to assess the effectiveness of antiatherosclerotic therapies in sequential studies. It seems that the future of nuclear molecular imaging is becoming ever more interesting.

\section{References}

1. Tzolos E, Kwiecinski J, Lassen ML et al (2020) Observer repeatability and interscan reproducibility of $18 \mathrm{~F}$-sodium fluoride coronary microcalcification activity. J Nucl Cardiol. https://doi. org/10.1007/s12350-020-02221-1

2. Derlin T, Richter U, Bannas P, Begemann P, Buchert R, Mester J, Klutmann S (2010) Feasibility of 18F-sodium fluoride PET/CT for imaging of atherosclerotic plaque. J Nucl Med 51:862-865

3. Høilund-Carlsen PF, Sturek M, Alavi A, Gerke O (2020) Atherosclerosis imaging with ${ }^{18} \mathrm{~F}$-sodium fluoride PET: State-ofthe-art review. Eur J Nucl Med Mol Imaging 47:1538-1551

4. de Oliveira-Santos M, Castelo-Branco M, Silva R, Gomes A, Chichorro N, Abrunhosa A, Donato P, de Lima JP, Pego M, Gonçalves L, Ferreira MJ (2017) Atherosclerotic plaque metabolism in high cardiovascular risk subjects: A subclinical atherosclerosis imaging study with (18)F-NaF PET-CT. Atherosclerosis 260:41-46

5. Raggi P, Senior P, Shahbaz S, Kaul P, Hung R, Coulden R, Yeung R, Abele J (2019) (18)F-Sodium fluoride imaging of coronary atherosclerosis in ambulatory patients with diabetes mellitus. Arterioscler Thromb Vasc Biol 39:276-284

6. Guaraldi G, Milic J, Prandini N, Ligabue G, Esposito F, Ciusa G, Malagoli A, Scaglioni R, Besutti G, Beghetto B, Nardini G, Roncaglia E, Mussini C, Raggi P (2020) 18Fluoride-based molecular imaging of coronary atherosclerosis in HIV infected patients. Atherosclerosis 297:127-135

7. Lee JM, Bang J-I, Koo B-K, Hwang D, Park J, Zhang J, Yaliang T, Suh M, Paeng JC, Shiono Y, Kubo T, Akasaka T (2017) Clinical relevance of (18)F-sodium fluoride positron-emission tomography in noninvasive identification of high-risk plaque in patients with coronary artery disease. Circ Cardiovasc Imaging. https://doi.org/ 10.1161/CIRCIMAGING.117.006704

8. Creager MD, Hohl T, Hutcheson JD, Moss AJ, Schlotter F, Blaser MC, Park M-A, Lee LH, Singh SA, Alcaide-Corral CJ, Tavares AAS, Newby DE, Kijewski MF, Aikawa M, Di Carli M, Dweck MR, Aikawa E (2019) (18)F-Fluoride signal amplification identifies microcalcifications associated with atherosclerotic plaque instability in positron emission tomography/computed tomography images. Circ Cardiovasc Imaging 12:e007835

9. Joshi NV, Vesey AT, Williams MC, Shah ASV, Calvert PA, Craighead FHM, Yeoh SE, Wallace W, Salter D, Fletcher AM, Van Beek EJR, Flapan AD, Uren NG, Behan MWH, Cruden NLM, Mills NL, Fox KAA, Rudd JHF, Dweck MR, Newby DE (2014) 18F-fluoride positron emission tomography for identification of ruptured and high-risk coronary atherosclerotic plaques: A prospective clinical trial. Lancet 383:705-713

10. Kwiecinski J, Tzolos E, Adamson PD et al (2020) Coronary 18Fsodium fluoride uptake predicts outcomes in patients with coronary artery disease. J Am Coll Cardiol 75:3061-3074

11. Agatston AS, Janowitz WR, Hildner FJ, Zusmer NR, Viamonte M Jr, Detrano R (1990) Quantification of coronary artery calcium using ultrafast computed tomography. J Am Coll Cardiol 15:827832

Publisher's Note Springer Nature remains neutral with regard to jurisdictional claims in published maps and institutional affiliations. 